\title{
Sub-cloning of Zinc Transporter Gene for Genetic Transformation to Improve Zinc Nutrient Status in Crop Plants
}

\author{
B. R. Mathapati ${ }^{1 *}$, R. Yamunarani ${ }^{2}$, K. N. Geetha ${ }^{3}$ and A. G. Shankar ${ }^{1}$ \\ ${ }^{1}$ Dept. of Crop Physiology, ${ }^{3}$ Dept. of Agronomy, University of Agricultural Sciences, GKVK, Bangalore, \\ Karnataka (560 065), India \\ ${ }^{2}$ Dept. of Plant Pathology, University of Arkansas, Fayetteville, AR (72 701), USA
}

\section{Article History}

Manuscript No. AR1362

Received in $30^{\text {th }}$ March, 2015

Received in revised form $29^{\text {th }}$ May, 2015

Accepted in final form $5^{\text {th }}$ June, 2015

\section{Correspondence to}

*E-mail: rajeshwari.cph@gmail.com

\section{Keywords}

Biofortification, zinc transporters, gateway cloning

\begin{abstract}
Nutrient deficiency stress is one of the major stresses limiting the crop productivity. Among the micronutrients, zinc deficiency is a widespread problem in plants as well as humans. In order to overcome zinc deficiency in human, the cost effective intervention would be to biofortify the food crops with zinc. While this approach heavily relies on the available knowledge of zinc homeostasis mechanisms in plants. Genetically modified plants developed by modulation of genes involved in zinc homeostasis, or genes influencing bioavailability, have shown promising results. Hence an attempt was made to sub-clone OsZIP1 zinc transporter gene of rice (Oryza sativa), so that the trans-gene construct could be subsequently used for genetic transformation of crop plants to accumulate more zinc. OsZIP1 is a high affinity zinc transporter gene, known to be overexpressed under zinc deprived conditions. Thus incorporation of this gene in crop plants would allow the plants to accumulate zinc even under zinc deficient conditions. In the absence of genetic variability in the crop plants for zinc content, which would limit breeding for zinc rich crops, transgenic development would provide a better alternative.
\end{abstract}

\section{Introduction}

Nutrient deficiency is always counted as one of the major limiting factor in crop productivity, though the requirement by the plant varies with type of the nutrient. Among several nutrients required by the plants for its growth, micronutrient, Zinc ( $\mathrm{Zn}$ ) is essential, as it an integral co-factor of over 300 enzymes, which are involved in biosynthesis and turnover of proteins, nucleic acids, carbohydrates and lipids in plants. Apart from this Zinc can regulate transcription directly through effects on DNA/RNA binding, and also through sitespecific modifications, regulation of chromatin structure, RNA metabolism and protein-protein interactions (Englbrecht et al., 2004). But, about half the agricultural soils in India and Turkey, a third of agricultural soils in China, and most soils in Western Australia lack sufficient Phyto-available Zn (Broadley et al., 2007; Ismail et al., 2007). Such soil conditions, not only limits the crop productivity but, also short supply Zinc ( $\mathrm{Zn}$ ) for human nutrition. Estimates points that, approximately one-third of the World's population is suffering from zinc deficiency (Hotz and Brown, 2004). In human beings Zinc deficiency leads to impaired growth, immune dysfunction, increased child morbidity and mortality, adverse pregnancy outcomes, and abnormal neuro-behavioural development. Zinc deficiency is directly related to the severity and frequency of diarrhoeal episodes, a major cause of child death (WHO/UNICEF, 2004). The body of evidence on zinc deficiency has accumulated to the degree that zinc fortification has been jointly recommended by WHO/FAO (2006).

Thus the possible ways to address Zinc deficiency in humans is through dietary diversification, mineral supplementation, food fortification and biofortification. While, biofortification is considered as a cost effective and long lasting solution to overcome zinc malnutrition (Mayer et al., 2008). Biofortification relies on the plant's biosynthetic (vitamins) or physiological (minerals) capacity to produce or accumulate the desired nutrients (Mayer et al., 2008). This approach to enhance $\mathrm{Zn}$ levels in edible parts of the plant can be achieved by conventional, molecular breeding and transgenic approaches. The limitation to conventional breeding would be the narrow genetic variability for $\mathrm{Zn}^{2+}$ content in grains. One can go for mutational approaches to widen the genetic variability and use the best mutant line with high $\mathrm{Zn}$ as donor parent for further 
breeding work. While one more approach would be application of zinc fertilizers which is not a totally successful strategy in alleviating $\mathrm{Zn}$ deficiency because of agronomic (i.e. subsoil constraints, disease interactions), economic (i.e. unavailability of $\mathrm{Zn}$ fertilizers for poor farmers) and environmental (i.e. pollution associated with excessive fertilizer use) factors (Hacisalihoglu and Kochian, 2003). Molecular genetic approaches would be more efficient and reliable solution to $\mathrm{Zn}$ deficiency limitations to crop production which would reduce fertilizer inputs and protect the environment as well.

A metal ion such as $\mathrm{Zn}$ has to travel a long way from the soil before it enters edible parts of the plant and before we can predict the effect of biofortication strategies, we need to know more about biological processes that govern the uptake and distribution of this ion in plants. A metal's availability for plant uptake, that is, its bioavailability, is governed by a complex interplay between the chemical properties of the metal cations, the composition and physicochemical properties of the soil, microbial activity and plant roots (Antunes et al., 2006). Transport of bio available metal ions across the plasma membrane is the first step in metal uptake and accumulation. Since zinc plays varied role in cells and because it cannot passively diffuse across cell membranes, it must be transported into the intracellular compartments of a cell where it is required for $\mathrm{Zn}$ dependent processes. A group of proteins called $\mathrm{Zn}$ transporters is dedicated to the transport of $\mathrm{Zn}$ across biological membranes. The role of membrane transporters is central to $\mathrm{Zn}$ homeostasis, being required for uptake, compartmentalization, vascular loading and delivery into organelles for utilization and a number of protein families have been implicated in $\mathrm{Zn}$ transport in plants. The genes encoding many of these proteins responsible for $\mathrm{Zn}$ uptake, sequestration and redistribution within the plant show up-regulated expression during $\mathrm{Zn}$ deficiency. These include ZIPs (Milner and Kochian, 2008), HMAs (van de Mortel et al., 2006), YSLs (Suzuki et al., 2006), MTPs (Arrivault et al., 2006), ZIF1 (Haydon and Cobbett, 2007), FRD3 (van de Mortel et al., 2006).

A transgenic approach to increase the $\mathrm{Zn}$ content of cereal grains might involve the manipulation of transporters involved in $\mathrm{Zn}$ translocation (Ramesh et al., 2004). With respect to $\mathrm{Zn}$ uptake, translocation and deposition, a predominant role seems to be played by members of the ZIP family (Ramesh et al., 2003). It is also studied that most $Z^{2+}$ influx to the cytoplasm is mediated by ZIPs (ZIP1, ZIP3 and ZIP4) (Palmgren et al., 2008). Additionally there is one of the studies suggesting that OsZIP1 has been well characterized as high affinity zinc transporter which is responsible for uptake and translocation (Ramesh et al., 2003) Hence OsZIP1 a high affinity zinc transporter was selected for sub-cloning in our study.

\section{Materials and Methods}

All these experimentations mentioned in the study were carried out in Department of Crop Physiology, UAS, Bangalore for a period of one year from 2009 to 2010 under molecular laboratory conditions. The various procedures followed for sub-cloning by Gateway cloning technology have been discussed below.

\subsection{Gene source}

The gene OsZIP1 (Oryza sativa Zinc regulated transporter, Iron regulated transporter-like Proteins1) was procured from RGRC (Rice Genome Research Centre), Japan. It was cloned into $\mathrm{T} / \mathrm{A}$ vector, $\mathrm{pTZ}$ 57R/T.

\subsection{Preparation of DB3.1 Escherichia coli (E. coli) competent cells}

Gateway compatible DB3.1 E.coli cells were grown in $3 \mathrm{ml}$ Luria Bertani (LB) liquid medium containing $10 \mathrm{~g} \mathrm{~L}^{-1}$ Bactotryptone, $5 \mathrm{~g} \mathrm{~L}^{-1}$ Bacto yeast extract, $10 \mathrm{~g} \mathrm{~L}^{-1} \mathrm{NaCl}$, $\mathrm{pH} 7.0$ and without antibiotics using $50 \mu \mathrm{L}$ of the starter culture at $37^{\circ} \mathrm{C}$. $200 \mu \mathrm{L}$ from the $3 \mathrm{ml}$ culture was inoculated into 200 $\mathrm{mL}$ of $2 \mathrm{X}$ YT medium $\left(10 \mathrm{~g} \mathrm{~L}^{-1}\right.$ Tryptone; $10 \mathrm{~g} \mathrm{~L}^{-1}$ Yeast extract; $5 \mathrm{~g} \mathrm{~L}^{-1} \mathrm{NaCl}, \mathrm{pH} 7.0$ ) and grown at $37^{\circ} \mathrm{C}$ for $2-3$ hours until it reaches an OD of 0.3 to 0.6 . The culture was centrifuged at $3000 \mathrm{rpm}$ and the pellet was resuspended in $1 / 20^{\text {th }}$ the volume of TSB-Transformation and Storage Buffer. This step was repeated twice. The resuspended pellet was incubated on ice for $10 \mathrm{~min}$ and then frozen immediately in liquid nitrogen and stored at $-70{ }^{\circ} \mathrm{C}$.

\subsection{Preparation of electro competent Agrobacterium tumifaciens}

Electroporation competent $A$. tumifaciens (EHA105) cells were prepared according to Shen and Ford (1989). A single colony of A. tumifaciens (EHA105) was inoculated in $3 \mathrm{ml}$ of LB medium, incubated at $28{ }^{\circ} \mathrm{C}$ for $16 \mathrm{~h}$ maintained at $250 \mathrm{rpm}$ and then, resuspended in fresh LB medium $(50 \mathrm{ml})$ and further grown to an $\mathrm{OD}_{600}$ of 0.5 . The cell culture was cooled on ice for $30 \mathrm{~min}$ and centrifuged at $5000 \mathrm{rpm}, 4{ }^{\circ} \mathrm{C}$ for $5 \mathrm{~min}$. The pellet obtained was washed successfully in 1.0, 0.5, 0.2 and 0.1 culture volumes of cold $10 \%(\mathrm{v} / \mathrm{v})$ glycerol and suspended in $0.01 \mathrm{v}$ of $10 \%(\mathrm{v} / \mathrm{v})$ Glycerol. Aliquots $(40 \mu \mathrm{l})$ of the last suspension were made, shock frozen in liquid nitrogen and stored at $-70^{\circ} \mathrm{C}$ as electro competent $A$. tumifaciens.

\subsection{Gateway cloning technique}

\subsubsection{BP Reaction for generation of entry clone with OsZIP1}

$\mathrm{BP}$ reaction facilitates recombination of an at $\mathrm{B}$ substrate (attB-PCR product) with an attP substrate (DONR vector) to create an attL containing entry clone. The OsZIP1 gene was 
amplified using gene specific primers with att $\mathrm{B} 1$ and $\mathrm{B} 2$ sites. The PCR product was purified and cloned into $\mathrm{pDONR}^{221}$ by $\mathrm{BP}$ clonase ${ }^{\mathrm{TM}}$-mediated recombination reaction and subsequently transformed to E. coli (DB3.1) competent cells to obtain the corresponding entry clones. Successful cloning of gene fragments was confirmed by PCR amplification using gene specific primers. The BP reaction created an entry clone containing $O s \mathrm{ZIP} 1$, flanked by at $t \mathrm{~L}$ sites.

\subsubsection{LR Reaction for generation of Expression clone with OsZIP1}

LR reaction facilitates recombination of an att $\mathrm{L}$ substrate (entry clone) with an $a t t \mathrm{R}$ substrate (destination vector) to create an attB-containing expression clone. The OsZIP1 gene from the entry clone was sub-cloned into suitable Gateway ready destination vector, $\mathrm{pK} 7 \mathrm{WG} 2.0$ using LR clonase $^{\mathrm{TM}}$ mediated recombination reaction. In $\mathrm{LR}$ reaction, at $\mathrm{L}$ sites in entry vector recombine with the $a t t \mathrm{R}$ sites in the destination vector. The final product of the reaction, the expression clone, will regain the original att $\mathrm{B}$ sites and can be used for plant transformation studies. Further, success of LR reaction was confirmed by PCR amplification of the clones used with at $\mathrm{B}$ primers (Bushman et al., 1985).

\subsection{Agrobacterium Mobilization}

For electroporation, $2 \mathrm{ng}$ of plasmid DNA was added to 100 $\mu \mathrm{L}$ of electrocompetent Agrobacterium cells (EHA105) and homogenized by gently mixing with pipette several times and then transferred to the pre-chilled cuvette. Electroporation (Electroporator 2510, Eppendorf $^{\circledR}$, Germany) was done at $1440 \mathrm{~V}$ with time constant of $5 \mathrm{~ms}$. Immediately after electroporatrion, the electroporated cells were added into a sterile tube containing $900 \mu \mathrm{L}$ of LB medium and incubated at $28^{\circ} \mathrm{C}$ for $2 \mathrm{hrs}$, after initial incubation cells were plated on the minimal selective $\mathrm{AB}$ media plate and incubated at $28^{\circ} \mathrm{C}$ for 12 to $72 \mathrm{hrs}$. Transformation was confirmed, colonies were screened for the presence of OsZIP1 gene by colony PCR using gene specific primers.

\section{Results and Discussion}

\subsection{Gateway cloning Technology}

Much progress has recently been made towards identifying the molecular mechanisms of zinc transport in plants (Gaither and Eide, 2001). As a result, several possible candidate genes are now available for engineering zinc efficiency and for increasing the zinc content in the edible plant parts. Among these, candidate genes of divalent cation transporters from the plasma membrane and the vacuole include the ZIP family of zinc and iron transporters (Maser et al., 2001). The over-expression and engineering of these transporters in plant will determine if this approach will lead to solutions for increasing zinc uptake when available. For which appropriate gene cloning method is equally important. In our study we demonstrate successful cloning of OsZIP1 through gateway cloning technology. Gateway cloning technology when compared to traditional cloning methodology, facilitates high-throughput cloning of target sequences by making use of the bacteriophage lambda site-specific recombination system. Target sequences are first cloned into an entry vector that is commercially available and then recombined into destination vectors for expression in different experimental organisms. Gateway technology has been employed by a number of plant laboratories for promoter specificity analyses, protein localization studies, protein/ protein interaction studies, constitutive or inducible protein expression studies, gene knockdown by RNA interference, or affinity purification experiments (Earley et al., 2006).The cloning results have been discussed further.

\subsection{Confirmation of OsZIP1 in T/A vector}

We cloned OsZIP1 gene under constitutive promoter by gateway cloning technology with kanamycin as plant selectable marker. Gene specific primers were designed with adapter sites in the UTR of OsZIP1 sequence and amplification was carried out under standard PCR conditions. Amplified products were cloned into T/A vector, pTZ57R/T. The presence of OsZIP1 in T/A was confirmed by PCR with gene specific primers (Figure 1a). Restriction enzyme digestion can be performed to determine the correct insert (Green and Sambrook, 2012a). Accordingly we confirmed the presence of cloned gene OsZIP1 in T/A vector by restrict digesting it with BamH I and Sac I to release OsZIP1 (Figure1b).

\subsection{Generation of Entry clone and expression clone with OsZIP1}

The OsZIP1 gene was amplified using gene specific primers with attB1 and B2 sites. The PCR product was purified and cloned into $\mathrm{pDONR}^{221}$ vector by BP reaction and subsequently 1a

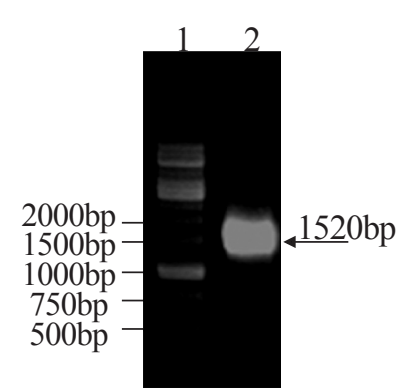

Lane 1-1 kb DNA ladder Lane 2-plasmid amplified with gene specific primers

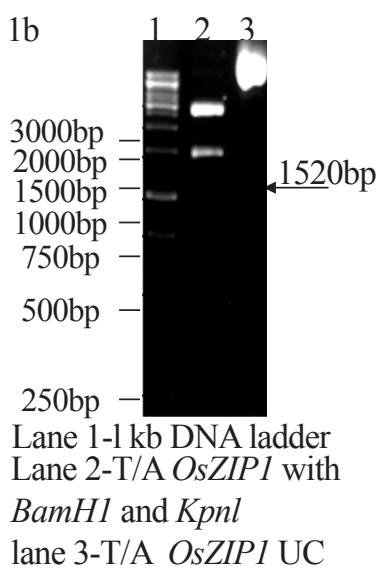

Figure1a: Agarose gel showing amplified fragment of OsZIP1 fragment from cloning vector; $1 \mathrm{~b}$ : Restriction analysis of OsZIP1 in T/A-vector 
transformed to $E$. coli (DB3.1) cells to obtain the corresponding entry clones. The presence of the DNA insert can also be determined by screening bacterial colonies using PCR. The primers may be insert-specific, vector-specific, or both to detect the insert. Colony screening by PCR is suitable for inserts shorter than $3 \mathrm{~kb}$ (Green and Sambrook, 2012b). Since our insert size was $1.5 \mathrm{~kb}$, thus successful cloning of gene fragments was confirmed by colony PCR using gene specific primers (Figure 2). Also the presence of insert was reconfirmed by restriction analysis with $B g l I I$ and Pst $I$ i.e., the sites within the gene (Figure 3 ). The most accurate way to verify the recombinant colonies is by sequencing (Green and Sambrook, 2012c). Hence we sequenced the PCR product for further confirmation. The BP reaction created an entry clone containing OsZIP1, flanked by attL sites. The entry clone plasmid carrying OsZIP1, incubated with the destination vector, pK7WG2.0 in the presence of LR clonase enzyme produced an expression clone. The expression clone thus obtained was transformed to competent $E$. coli cells and selected on antibiotic selection media. The surviving colonies were PCR amplified with gene specific primers to confirm cloning (Figure 4).

Restriction enzyme analysis was also performed in the

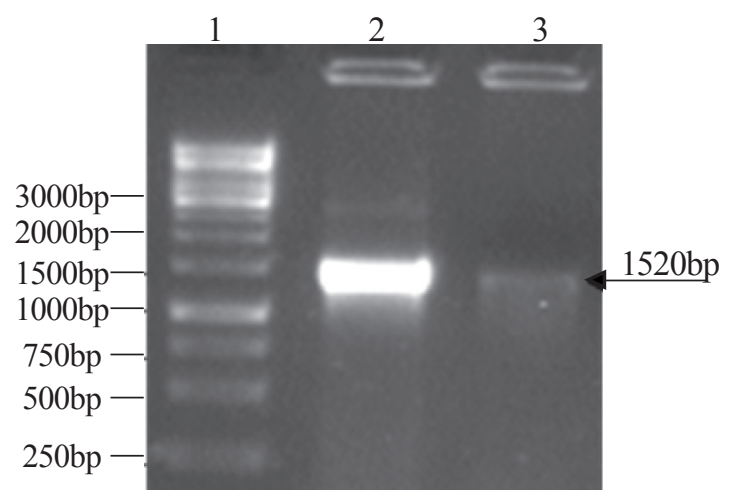

Lane 1: $1 \mathrm{~kb}$ DNA ladder; Lane 2 and 3: Positive colonies

Figure 2: OsZIP1 in Gateway entry clone, following BP reaction

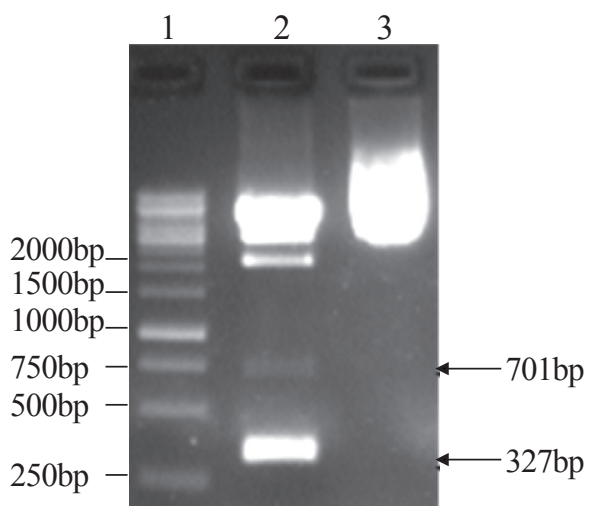

Lane 1: 1 kb DNA ladder; Lane 2:Entry clone digested with $B g l$ II Pst I; Lane 3-Entry clone uncut

Figure 3: Restriction analysis of OsZIP1 in entry clones expression vector with $B g l I I$ and Pst I i.e., the sites within the gene to confirm for the presence of OsZIP1 (Figure 5). The LR reaction created an expression clone carrying OsZIP1. (Figure 6). portrays the pictorial representation of the T-DNA carrying OsZIP1 in pK7WG2.0 expression vector.

\subsection{Mobilization of OsZIP1 in destination Vector into Agrobacterium}

OsZIP1 in the destination vector was mobilised into Agrobacterium competent cells by electroporation. Transformed cells were confirmed for the presence of the gene by colony

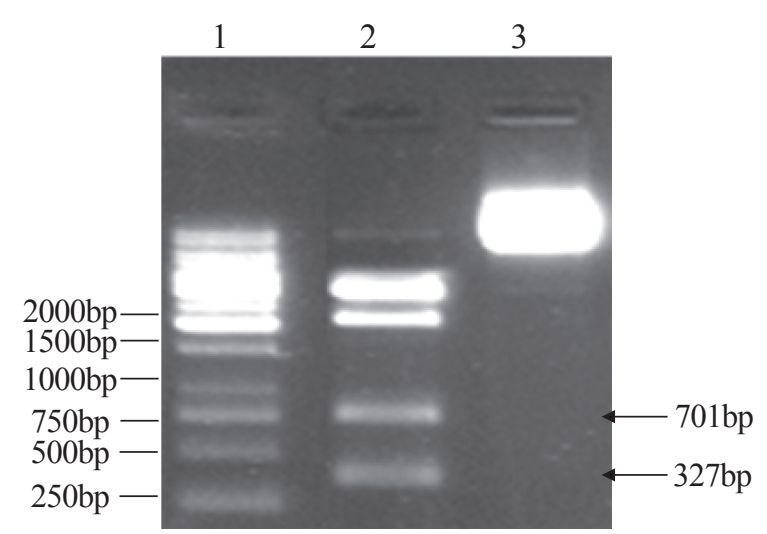

Lane 1: 1 kb DNA ladder; Lane 2: Recombinant clone digested with Bgl II and Pst I; lane 3: Recombinant clone uncut

Figure 4: Restriction analysis of OsZIP1 in pK7WG2.0, GATEWAY destination vector

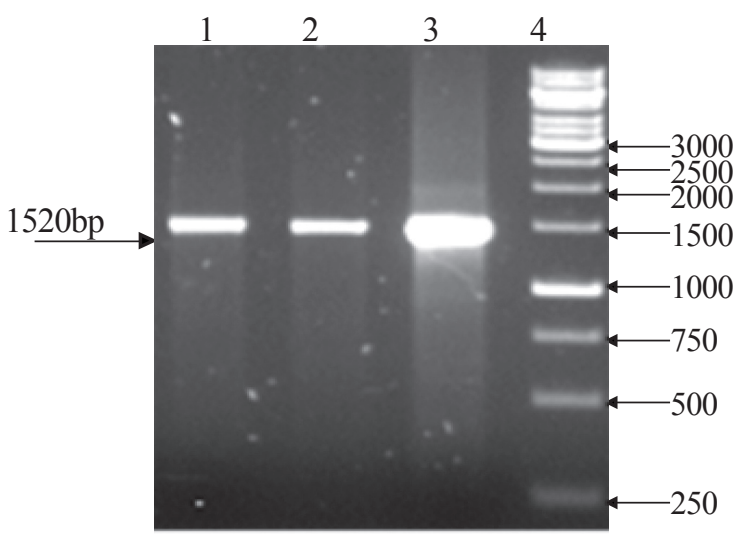

Lane 4: $1 \mathrm{~kb}$ DNA ladder; Lane 1, 2 and 3: positive colonies

Figure 5: OsZIP1 in Gateway destination vector, following LR reaction

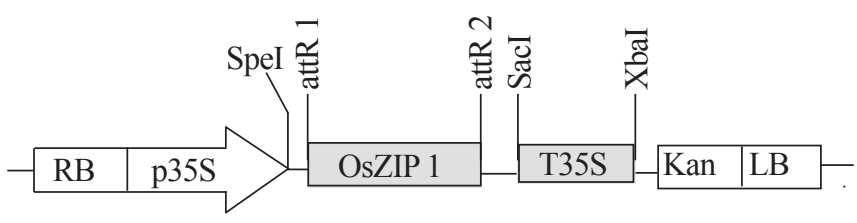

Figure 6: Schematic representation of T-DNA of OsZIP1 in pK7WG2.0, gateway destenation vector with Kanamycin as plant selectable marker 
PCR using gene specific primers (Figure 7). There are reports which show that overexpression of ZIP1, an Arabidopsis $\mathrm{Zn}$ transporter, leads to 2-fold higher $\mathrm{Zn}$ concentrations in seeds and shoots of transgenic wheat (Ramesh et al., 2004). Another study by Ishimaru et al. (2007) reports that, OsZIP4 constitutively overexpressed plants accumulated 10 times more $\mathrm{Zn}$ in their roots compared with the vector control. Thus we can speculate that, OsZIP1 being a high affinity zinc transporter (Ramesh et al., 2003), overexpressing it would lead to increase in zinc content in plant parts to a substantial level. Hence the expression vector containing OsZIP1 has to be transformed into a suitable crop plant to increase crop's zinc accumulation potential.

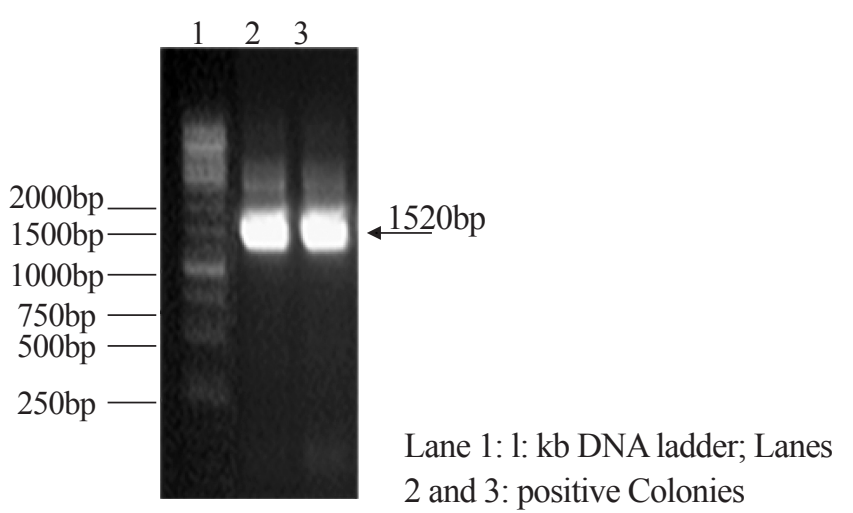

Figure 7: Agarose gel electrophoresis of colony PCR analysis of positive recombinant clones in Agrobacterium

\section{Conclusion}

OsZIP1, a high affinity transporter involved in uptake and translocation of zinc was being cloned into the Gateway destination vector pK7WG2.0 with kanamycin as plant selectable marker. Agrobacterium harboring OsZIP1 expression vector provides a potential starter material for transgenic development. This vector can be transformed into a suitable crop plant, where constitutive expression of OsZIP1 will increase the zinc uptake of the crop. Based on molecular and physiological characterization, the best performing transgenic event can be selected for varietal development.

\section{References}

Antunes, P.M., Berkelaar, E.J., Boyle, D., Hale, B.A., Hendershot, W., Voigt, A., 2006. The biotic ligand model for plants and metals: technical challenges for field application. Environment Toxicology Chemistry 25, 875-882.

Arrivault, S., Senger, T., Kramer, U., 2006. The Arabidopsis metal tolerance protein, AtMTP3 maintains metal homeostasis by mediating $\mathrm{Zn}$ exclusion from the shoot under Fe deficiency and $\mathrm{Zn}$ oversupply. Plant Journal $46,861-879$.
Broadley, M.R., White, P.J., Hammond, J.P., Zelko, I., Lux, A., 2007. Zinc in plants. New Phytologist 173, 677-702.

Bushman, W., Thompson, J.F., Vargas, L., Landy, A., 1985. Control of directionality in lambda site specific recombination. Science 230, 906-911.

Earley, K.W., Haag, J.R., Pontes, O., Opper, K., Juehne, T., Song, K., Pikaard, C.S., 2006.Gateway-compatible vectors for plant functional genomics and proteomics. Plant Journal 45(4), 616-29.

Englbrecht, C.C., Schoof, H., Böhm, S., 2004. Conservation, diversification and expansion of $\mathrm{C}_{2} \mathrm{H}_{2}$ zinc finger proteins in the Arabidopsis thaliana genome. BMC Genomics 5,39 .

Gaither, L.A., Eide, D.J., 2001. Eukaryotic zinc transporters and their regulation. Biometals 14, 251-270.

Green, R.M., Sambrook, J., 2012a. Molecular cloning, A Laboratory manual (4 $4^{\text {th }}$ Edn.). Cold Spring Harbor Laboratory Press, New York, 1249.

Green, R.M., Sambrook, J., 2012b. Molecular cloning, A Laboratory manual (4 $4^{\text {th }}$ Edn.). Cold Spring Harbor Laboratory Press, New York, 531.

Green, R.M., Sambrook, J., 2012c. Molecular cloning, A Laboratory manual ( $4^{\text {th }}$ Edn.). Cold Spring Harbor Laboratory Press, New York, 764.

Hacisalihoglu, G., Kochian, L.V., 2003. How do some plants tolerate low levels of soil zinc? Mechanisms of zinc efficiency in crop plants. New Phytologist 159, 341350 .

Haydon, M.J., Cobbett, C.S., 2007, A novel major facilitator superfamily protein at the tonoplast influences zinc tolerance and accumulation in Arabidopsis. Plant Physiology 143, 1705-1719.

Hotz, C., Brown, K.H., 2004, Assessment of the risk of zinc deficiency in populations and options for its control. Food Nutrition Bulletin 25, 94-204.

Ishimaru, Y., Masuda, H., Suzuki, M., Bashir, K., Takahashi, M., Nakanishi, H., Mori, S., Nishizawa, N.K., 2007. Overexpression of the OSZIP4 zinc transporter confers disarrangement of zinc distribution in rice plants, Journal of Experimental Botany 58, 2909-2915.

Ismail, A.M., Heuer, S., Thomson, M.J., Wissuwa, M., 2007. Genetic and genomic approaches to develop rice germplasm for problem soils. Plant and Soil 65, 547570.

Maser, P., Thomine, S., Schroeder, J.I., 2001. Phylogenetic relationships within cation transporter families of Arabidopsis. Plant Physiology 126, 1646-1667.

Mayer, J.E., Wolfgang, H.P., Peter, B., 2008. Biofortified crops to alleviate micronutrient malnutrition. Current Opinion in Plant Biology 11, 1-5. 
Milner, M.J., Kochian, L.V., 2008. Investigating heavy-metal hyperaccumulation using Thlaspi caerulescens as a model system. Annals of Botany 102, 3-13.

Palmgren, M.G., Clemens, S., Williams, L.E., Krämer, U., Borg, S., Schjorring, J.K., Sanders, D., 2008. Zinc biofortification of cereals: problems and solutions. Trends in Plant Science 13, 464-473.

Ramesh, S.A., Choimes, S., Schachtman, D.P., 2004. Overexpression of an Arabidopsis zinc transporter in Hordeum vulgare increases short-term zinc uptake after zinc deprivation and seed zinc content. Plant Molecular Biology 54, 373-385.

Ramesh, S.A., Shin, R., Eide, D.J., Schachtman, D.P., 2003. Differential metal selectivity and gene expression of two zinc transporters from rice. Plant Physiology 133, 126-134.

Shen, W.J., Forde BG., 1989. Efficient transformation of Agrobacterium spp. by high voltage electroporation. Nucleic Acids Research 17, 8385.

Suzuki, M., Takahashi, T., Tsukamoto, T., Watanabe, S., Matsuhashi, S., Yazaki, J., Kishimoto, N., Kikuchi, S.,
Nakanishi, H., Mori, S., 2006. Biosynthesis and secretion of mugineic acid family phytosiderophores in zincdeficient barley. Plant Journal 48, 85-97.

Van De Mortel, J.E., Villanueva, L.A., Schat, H., Kwekkeboom, J., Coughlan, S., Moerl, P.D., Ver Loren Van Themaat, E., Koornneef, M., Aarts, M.G.M., 2006. Large expression differences in genes for iron and zinc homeostasis, stress response, and lignin biosynthesis distinguish roots of Arabidopsis thaliana and the related metal hyperaccumulator Thlaspi caerulescens. Plant Physiology 142, 1127-1147.

WHO/UNICEF, 2004. Clinical Management of Acute Diarrhea. The United Nations Children's Fund/World Health Organization. Available from http://whqlibdoc. who.int/hq/2004/WHO_FCH_CAH_04.7.pdf.

WHO/FAO, 2006. Guidelines on Food Fortification with Micronutrients. World Health Organization and Food and Agricultural Organization of the United Nations. Available from http://www.who.int/nutrition/ publications/guide_food_fortification_micronutrients. pdf. 